\title{
NAA Algerian Laboratory Evaluation Processed by WEPAL and IAEA during 2011-2012
}

\author{
Lylia Hamidatou, Hocine Slamene, Tarik Akhal, Samir Begaa, Mohammed Messaoudi, \\ Zouranen Boussaad \\ Neutron Activation Analysis Department, Nuclear Research Centre of Birine, Djelfa, Algeria. \\ Email: lylia.h@hotmail.fr
}

Received September $11^{\text {th }}, 2013$; revised October $12^{\text {th }}, 2013$; accepted October $18^{\text {th }}, 2013$

Copyright (C) 2013 Lylia Hamidatou et al. This is an open access article distributed under the Creative Commons Attribution License, which permits unrestricted use, distribution, and reproduction in any medium, provided the original work is properly cited.

\begin{abstract}
Participation in inter-comparison programs is an important process to enhance the accuracy and precision of the analytical techniques used in the laboratories. At Es-Salam Research Reactor, our laboratory uses two functional analytical techniques such as INAA and $\mathrm{k}_{0}$-INAA in the research projects and for the completion of the service works. Recently, our laboratory has participated in two inter-comparison tests organized by IAEA within the framework of the AFRA project to assess the analytical performance of eighteen (18) African analytical laboratories participating in the RAF/4/ 022 project, Enhancement of Research Reactor Utilization and Safety by taking part in analytical proficiency testing IAEA in conjunction with WEPAL, the Wageningen Evaluating Programs for Analytical Laboratories. The Proficiency Testing tests related to the determination of major, minor and trace elements in materials of the International Soil and Plant Analytical Exchange (Wepal codes ISE, IPE), were held in the fourth quarter of 2011 and the first quarter of 2012, respectively. Concentrations of thirty (30) elements such as $\mathrm{Al}, \mathrm{As}, \mathrm{Ba}, \mathrm{Br}, \mathrm{Ca}, \mathrm{Cd}, \mathrm{Ce}, \mathrm{Co}, \mathrm{Cr}, \mathrm{Cs}, \mathrm{Fe}, \mathrm{Ga}, \mathrm{K}, \mathrm{La}, \mathrm{Mg}$, Mo, Mn, Na, Nd, Rb, Sb, Sc, Sr, Th, Ti, U, V, W, Zn, Zr were determined in ISE and IPE samples. All results were evaluated and reported in this paper.
\end{abstract}

Keywords: Laboratory; Evaluation; NAA Method; Performance; Accreditation; Proficiency Testing

\section{Introduction}

The Algerian research reactor (Es-Salam) is a $15 \mathrm{MW}$ heavy water reactor type, operating since 1992. Instrumental neutron activation analysis (INAA) was introduced in 1993 at the laboratory of the neutron activation analysis department, in Nuclear Research Centre of Birine, Algeria. In our research reactor, the $\mathrm{k}_{0}$-method was successfully developed using the HØGDAHL convention and WESTCOTT formalism [1,3]. In 2012, Hamidatou L et all reported in this paper " $\mathrm{k}_{0}$-NAA quality assessment in an Algerian laboratory by analysis of SMELS and four IAEA reference materials using Es-Salam Research reactor" the internal quality control of the $\mathrm{k}_{0}$-NAA technique [4]. The concept of QC/QA, internal and external validation is considered as an advanced stage in the life cycle of an analytical method. This technique was used for practical applications in several areas of life such as: nutrition, health related to environmental field, mining and industrial fields [5-7].
Recently, there is a growing interest in the use of the NAA method for trace element determination in the industrial sector. The richness of the service analytics in our NAA laboratory has been in the diversity of solid samples. The dominant method used has been neutron activation analysis at Es-Salam research reactor during 20 years of its activity. The viewpoint is that the neutron activation analysis remains the best tool to determine the contents of trace elements in all types of samples [8,9].

At Es-salam research reactor, the INAA and $\mathrm{k}_{0}$-NAA techniques are fully applied by researchers. In addition, the development of other analytical techniques based on the neutron activation is also an achievement such as the cyclic delayed neutron counting technique and the application of RNAA to the proportioning of iodine in food salt $[10,11]$. The NAA laboratory work is to make an effort to connect the unique features of NAA activities in a strategic way for the national goals. A reactor centre, whether it is in a university or other institution, is a substantial investment in the human and financial resources 
of a developing nation.

The current status of the NAA method, the analytical procedures and the nuclear activities of our laboratory are presented in the chapter "Concepts, Instrumentation and Techniques of Neutron Activation Analysis" newly published in the book: Imaging and Radioanalytical Techniques in Interdisciplinary Research-Fundamentals and Cutting-edge Applications [9].

A regular independent assessment of the technical performance of a laboratory is necessary to assure the validity of measurements or tests, and should be part of an overall quality strategy. The main objective of a PT scheme is to help the participant to assess the accuracy [12] of its measurements. In addition, participation in an appropriate PT scheme is required for laboratories seeking recognition of their competence through accreditation against the standard ISO/IEC 17025 [13] or ISO 15189 [14]. In some sectors participation in specific schemes can be mandatory [15].

PT schemes are operated for the benefit of the laboratory participants. However, other parties also have a legitimate interest in PT schemes. These include customers of analytical laboratory services, accreditation bodies, regulatory authorities and other end-users of the laboratory results. The authors, Isabel Taverniers and all reported in the publication "Trends in quality in the analytical laboratory: Analytical method validation and quality assurance", the different approaches to validation, gives attention to the different characteristics of method performance with the concepts of single-laboratory, or in house validation, inter-laboratory or collaborative study [16]. The basic use of PT is to assess the performance for the conduct of specific measurements and calibrations.

This paper focused our experience on the inter-laboratory exercises undertaking for the evaluation of the analytical laboratory competency during the last decade in particular for the two new Proficiency Testing rounds organized by the IAEA under the RAF/4/022 project [17] in conjunction with WEPAL, the Wageningen Evaluating Programs for Analytical Laboratories (www.wepal.nl) [18].

\section{Synopsis Competency Tests Participation of the NAA-CRNB Laboratory}

Our NAA research laboratory was participated in several inter-comparison tests organized in the frame work of AFRA Research Reactor Projects. In the first participations, the work of analysis is based on the inter-comparison results of African laboratories. The last PT testing participation was to evaluate our research laboratory among a great number reached 500 laboratories on an international scale. This contribution was carried out in the PT program launched by WEPAl organisation. In this context, a brief description was presented for all partici- pation.

\subsection{The AFRA IV-7 Proficiency Test 2003 Using CMIP-P1 Rock Materials}

Our first participation using NAA laboratory on the proficiency test was carried out in the frame work of the AFRAIV-7 project named CMIP-AFRA-P1 Test 2003. It was requested from the laboratories to determine the trace and minor elements in geological materials. The proficiency test study was organized by the CSIR-NML in collaboration with IAEA and NECSA for the laboratories of the Research Reactor Centres in Africa. About 11 laboratories from 5 countries were participated in this study for the determination of 16 trace and minor elements (Au, Ca, Cd, Co, Cr, Cs, Fe, K, Mn, Na, Ni, Pb, $\mathrm{Rb}, \mathrm{Th}, \mathrm{U}, \mathrm{Zn})$ in a rock-type test material. The analytical methods used in this study are INAA, EDXRF, GFAAS, IC and ICP-MS. This work aimed to illustrate the comparability of results produced by the participating laboratories [19]. The results of the proficiency testing exercises were evaluated by Experts to the IAEA and a follow-up Inter-comparison feedback Meeting was held in Algeria during 29 Nov-3 Dec 2003 [20].

\subsection{The AFRA IV-7 Proficiency Test 2005 Using Medicinal Plants and Aquatic-Biomonitors Materials}

Two years later, AFRA IV-7 (2005) was the second Proficiency Test within the AFRA IV-7 Research Reactor Project for Socio-economic development. Thirteen laboratories from eight countries were participated in this study. The laboratories were requested to analysis 31 elements in five biological materials that were distributed by the project. One of the distributed samples was an IAEA reference material (IAEA-155, Whey powder) to check the results of the nuclear analytical technique applied for all five materials. The focus of this project was on the evaluation of foodstuffs for their nutritive values, the determination of the element composition of medicinal plants and the analysis of aquatic-biomonitors for environmental monitoring, using nuclear and related analytical techniques, with neutron activation analysis as the common technique [21]. The results of the proficiency testing exercises were evaluated by Experts to the IAEA and a follow-up Inter-comparison feedback Meeting was held in Libya during 2005 [22].

\subsection{The AFRA IV-12 Proficiency Test 2007 Using Foodstuff, Medicinal Plants and Aquatic Biomonitors Materials}

The AFRAIV-12 Inter-laboratory Analysis Test 2007 was the third inter-laboratory analysis test within that project. The laboratories were asked to analyze about 43 
essential and toxic elements using nuclear and related analytical techniques, with neutron activation analysis as the common technique. Five materials were distributed to the participants representing foodstuff, medicinal plants and aquatic biomonitors according to the focus of the RAF/4/020 AFRA IV-12 (2006-2010) project [23].

For the first time, Es-Salam research reactor of Algeria had the opportunity to take part with two techniques INAA and $\mathrm{k}_{0}$-INAA for which the $\mathrm{k}_{0}$-NAA technique was newly developed (2004) in our department. Indeed, two sets of independent results obtained by INAA and $\mathrm{k}_{0}$-INAA techniques were sent for evaluation. Each technique was used as an analytical tool regarded as an independent laboratory while associating a number and a particular code in event the Algerian laboratories with $\mathrm{CRNB} / \mathrm{INAA}$ and $\mathrm{CRNB} / \mathrm{k}_{0}-\mathrm{NAA}$, respectively. The participating laboratories met to discuss their results in the presence of the experts of IAEA. All results obtained by the African analytical laboratories were evaluated by expects of the IAEA and the meeting for was held in Kenitra, Morocco from 14 to 18 July 2008 to discuss the results evaluations [24,25].

\subsection{WEPAL PT Scheme 2011.4-2012.1 Rounds in Conjunction with IAEA/AFRA Project}

The goal of this paper focuses the assessment of our scientific activities through the PT evaluation of the NAA laboratory. The principal actions carried out within the framework of the RAF/4/022 project: "Enhancement of Research Reactor Utilization and Safety" led to the evaluation of the African laboratories with the advantage to participate on the PT program of WEPAL. The Proficiency Testing rounds related to the determination of (trace) elements in soil and plant materials were held by WEPAL for which 4 ISE and 4 IPE samples have been used in each round during 2011/4 and 2012/1, respectively. WEPAL, a provider of such Inter-labortaory comparison schemes, is accredited by the Dutch Council for Accreditation, for compliance with the International Standard ISO17043:2010. The activity within IAEA AFRA RAF 4/022 coincided with similar assessments amongst European and Latin American analytical laboratories under RER 1007 and RLA 0037, respectively.

In this study, we aim to evaluate of the competency of our laboratory among the proficiency test enhancement of low and medium power research reactor (RR) utiliztion is often pursued by increasing the neutron activation analysis (NAA) activities. Over the years, the IAEA has stimulated the orientation of NAA groups worldwide on fields of application in which large amounts of samples may exist for analysis. Whereas the markets for NAA laboratories may have been identified, an underestimated problem remains the quality assurance and quality control (QA\&QC), which limits tremendously the commer- cial routine application of this powerful technique.

Indeed, the IAEA facilitated during 2011-2012 laboratories, participating in IAEA/AFRA project $\mathrm{RAF} / 4 / 022$ to assess their analytical performance by taking part in analytical proficiency testing IAEA in conjunction with WEPAL, the Wageningen Evaluating Programs for Analytical Laboratories. Two such rounds have been organized, and the results evaluated by the IAEA supported by Experts in nuclear and non-nuclear analytical techniques. Potential sources of error, technical and organizational, were identified for the individual laboratories, action plans for improvement were drafted and accepted, and the Agency was recommended continuing this approach for proficiency testing and evaluation as all participants highly valued the outcome of it.

The 18 participants were representatives of research reactor (RR) operating facilities and analytical laboratories in 9 African Member States (MSs). Of these, 6 are with operational RRs: Algeria, Egypt, Ghana, Morocco and South Africa; the other 3 MSs were: DRC, Libya and Sudan. Others participants were Nigeria, Cameroon Madagascar, Tanzania and Tunisia. The IAEA was supported in the evaluation and discussion of the results by two Experts.

Two functional analytical techniques applied in the NAA laboratory of Es-Salam research reactor are INAA and $\mathrm{k}_{0}$-INAA. Our vision is to take benefit of these rounds to assess the competency of our laboratory through the use the instrumental and the $\mathrm{k}_{0}$-standardized neutron activation analysis. Indeed, two techniques were applied to provide the analytical results. About 31 elements were analyzed in different samples of soil and plant materials of WEPAL. The unique possible approach is to make combination between INAA and $\mathrm{k}_{0}$-INAA results. It means that the final data sheets provided by our laboratory to WEPAL organism include some results obtained by $\mathrm{k}_{0}$-INAA technique and other by INAA technique. The results of analysis must be reported according to the specific forms for IPE and ISE reports. During the meeting on Inter-Comparison Feedback of NAA and other Analytical Techniques Proficiency Tests, AIEA Project/ RAF4/022 - Enhancing Research Reactor Utilization and Safety, 04-08 June 2012, Tunis, Tunisia, all participating laboratories have been presented their results with the same IAEA proposed form [26].

\section{Materials and Methods}

\subsection{IPE and ISE WEPAL Samples}

The global program of WEPAL included six sets of samples: ISE (International Soil-Analytical Exchange), IPE (International Plant-Analytical Exchange), SETOC (International Sediment Exchange for Tests on Organic Contaminants), MARSEP (International Manure and Re- 
fuse sample Exchange Program), BIMEP (International Biomass Exchange Program) and Q (Quasimeme Laboratory Performance Studies organic contaminants, metals, nutrients in seawater, sediment and biota).

Each quarter, sample kits are mailed to participating laboratories and data are analyzed to evaluate performance. Each mailing and subsequent data analysis is referred to as a round. The reference samples included in a kit are designated to cover a variety of analytical methods used by laboratories.

In the case of the AFRA IV-12-RAF4/022 project within the financial support of IAEA a total of sixteen materials were received from WEPAl organism during 2011-4 and 2012-1 periods. The materials representing different types of soil and plant named ISE and IPE. In each round the samples ISE and IPE are labelled from one to four. Table 1 illustrates the analyzed WEPAL samples covering plants and soils. Before receiving the WEPAL materials, all samples used in these rounds of the proficiency test have passed the homogeneity test [27-30].

\subsection{Instrumental Neutron Activation Analysis Method, INAA}

The unknown sample is irradiated together with a calibrator containing a known amount of the element(s) of interest. The calibrator is measured under the same conditions as the sample (sample-to-detector distance, equivalent sample size and if possible equivalent in composition). From comparison of the net peak areas in the two measured spectra the mass of the element of interest can be calculated [9]:

$$
\mathrm{m}_{\mathrm{x} \text { (unk })}=\mathrm{m}_{\mathrm{x}(\text { cal })} \cdot \frac{\left(\frac{\mathrm{N}_{\mathrm{p}}}{\mathrm{t}_{\mathrm{m}} \mathrm{e}^{-\lambda \mathrm{t}_{\mathrm{d}}} \cdot\left(1-\mathrm{e}^{-\lambda \mathrm{t}_{\mathrm{m}}}\right)}\right)_{\mathrm{unk}}}{\left(\frac{\mathrm{N}_{\mathrm{p}}}{\mathrm{t}_{\mathrm{m}} \mathrm{e}^{-\lambda \mathrm{t}_{\mathrm{d}}} \cdot\left(1-\mathrm{e}^{-\lambda \mathrm{t}_{\mathrm{m}}}\right)}\right)_{\mathrm{cal}}}
$$

in which $\mathrm{m}_{\mathrm{x} \text { (unk) }}, \mathrm{m}_{\mathrm{x}(\text { cal })}$ mass of the element of interest, in unknown sample and calibrator, respectively; in $g$ unit. In this procedure many of the experimental parameterssuch as neutron fluence rate, cross section and photopeak efficiency cancel out at the calculation of the mass and the remaining parameters are all known. This calibration procedure is used if the highest degree of accuracy is required. The relative calibration on basis of element calibrators is not immediately suitable for laboratories aiming at the full multi-element powers of INAA. It takes considerable effort to prepare multi-element calibrators for all 70 elements measurable via NAA with adequate degree of accuracy in a volume closely matching the size and the shape of the samples.

\subsection{The $\mathbf{k}_{0}$-Standardization Neutron Activation Analysis, $\mathbf{k}_{0}$-INAA}

The $\mathrm{k}_{0}$-based neutron activation analysis ( $\mathrm{k}_{0}$-NAA) technique, developed in 1970s, is being increasingly used for multielement analysis in a variety of matrices using reactor neutrons. In the $\mathrm{k}_{0}$-INAA the evaluation of the analytical result is based on the so-called $\mathrm{k}_{0}$-factors that are associated with each gamma-line in the gamma-spectrum of the activated sample. These factors replace nuclear constants, such as cross sections and gamma-emission probabilities, and are determined in specialized NAA laboratories. This technique has been reported to be flexible with respect to changes in irradiation and measuring conditions, to be simpler than the relative comparator technique in terms of experiments but involves more complex formulae and calculations, and to eliminate the need for using multi-element standards. The concentration of an element can be determined as:

$$
\begin{aligned}
\rho_{\mathrm{x}}(\mathrm{ppm})= & \frac{\left[\frac{\mathrm{C} / \mathrm{t}_{\mathrm{m}}}{\mathrm{SDCW}}\right]_{\mathrm{x}}}{\left[\frac{\mathrm{C} / \mathrm{t}_{\mathrm{m}}}{\mathrm{SDCW}}\right]_{\mathrm{Au}}} \cdot \frac{1}{\mathrm{k}_{0, \mathrm{Au}(\mathrm{x})}} \cdot \\
& \frac{\mathrm{G}_{\mathrm{th}, \mathrm{Au}} \mathrm{f}+\mathrm{G}_{\mathrm{epi}, \mathrm{Au}} \mathrm{Q}_{0, \mathrm{Au}(\alpha)}}{\mathrm{G}_{\mathrm{th}, \mathrm{x}} \mathrm{f}+\mathrm{G}_{\mathrm{epi}, \mathrm{x}} \mathrm{Q}_{0, \mathrm{x}(\alpha)}} \cdot \frac{\epsilon_{\mathrm{p}, \mathrm{Au}}}{\epsilon_{\mathrm{p}, \mathrm{x}}} \times 10^{6}
\end{aligned}
$$

where the indices $\mathrm{x}$ and $\mathrm{Au}$ refer to the sample and the monitor, respectively; WAu and $\mathrm{Wx}$ represent the mass of the gold monitor and the sample (in $\mathrm{g}$ ); $\mathrm{Np}$ is the measured peak area, corrected for dead time and true coincidence; S, D, C are the saturation, decay and counting factors, respectively; tm is the measuring time; Gth and Gepi are the self shielding correction for the thermal and

Table 1. List of plant and soil samples analyzed in this work.

\begin{tabular}{clcc}
\hline Type of matrials & \multicolumn{1}{c}{ IPE } & ISE \\
\hline $2011.4^{\mathrm{a}}$ & $\begin{array}{l}\text { Leek (allim porrum), Lucerne (Medicago Savitum), Oil palm leaves } \\
\text { (Elaeis Guineensis), Grass gr94 (Poaceae) }\end{array}$ & sandy soil, calcareous brown soil, clay, river clay \\
$2012.1^{\mathrm{b}}$ & $\begin{array}{l}\text { Maize (Zea mays), Banana leaves (Musa Sapientum) and Beech Leaf } \\
\text { (Fugus Sylvatica) }\end{array}$ & clay soil, loamy soil, sandy clay soil \\
\hline
\end{tabular}

${ }^{\mathrm{a} O c t-D e c}$ 2011. ' January-March 2012. 
epithermal neutrons, respectively.

\section{Experimental Procedure}

Triplicates were prepared from each sample of IPE and ISE. To be able to exploit both techniques INAA and $\mathrm{k}_{0}$-INAA in the same experiment, it is necessary to prepare the CRMs, RMs and gold monitors. In this work, the certified reference materials like CRM-GSV4, CRMNIST-1573a, CRM-GSD12 and reference material such as RM-AIEA-soil7 were used to determine the elemental concentrations by relative technique. In the other hand, the analytical results obtained of CRMs are the subject of internal quality control procedure.

All samples, monitors and standards were placed in clean cylindrical aluminium vials for long irradiation. The gold monitors Al- $0.1 \%$ Au alloy wire of $0.5 \mathrm{~mm}$ diameter provided by IRMM (Institute for Reference Materials and Measurements, Belgium) were prepared for $\mathrm{k}_{0^{-}}$ INAA utilisation. Data acquisition is performed usingGenie-2000 software from Canberra [31]. All spectra are deconvoluted with the commercial software HyperLab 2005 [32] with resulting to files peak table (*.PTF) and a spectrum (*.SPE) which are used as input for KayWare software [33]. This is a specific software package developed for $\mathrm{k}_{0}$-based NAA at DSM Resolve in the 1990s and at present commercialized by INW Gent and $\mathrm{k}_{0}$-Ware in the Netherlands.

\section{Results and Discussion}

The PT program is designated to complete, not replace, a participating laboratory's internal quality control (QC) program. In addition, the PT program may identify analytical problems when the laboratory's internal controls do not submit an application. To get reproducible results, Wepal recommends to the participants the determination of the moisture content in each sample. The procedure is explained in the quarterly IPE-ISE reports of WEPAl for which the materials must be drying during at least 3 hours at $105^{\circ} \mathrm{C}$ and cooling down in desiccator before weighing. The dry mass factors were determined for all plant and soil WEPAL samples. In our analytical techniques, the moisture content is directly introduced as an input values in the KayWin program.

The results are reported for the RAF/4/022 inter-laboratory proficiency test 2011-2012 and consequently evaluated by WEPAl. The final treatment of results for each type of samples ISE and IPE has to generate some parameter statistics such as: mean, standard deviation, median, MAD and Z-score.

The assessment of the PT rounds participation during 2011-4 and 2012-1 has been evaluated according to the sophisticated statistical methods which are required to obtain meaningful assessments. The model that is chosen calculates population characteristics (mean and standard deviation) from experimental datasets. The model uses an estimate for the probability density function of the measurement process and calculates a best fit based on all observed values. The analytical results of the analyzed materials are presented by three ways per element, sample and participant (laboratory) in the quarterly and annual reports ISE and IPE of WEPAL.

In this study, the evaluated results obtained by our laboratory were carried out by WEPAL for which the proficiency tests of the participant laboratories were processed by the tool of Z-scores. Using this approach, all Zscore values of our laboratory were presented graphically in the Figures 1-4. According to the evaluation processed by the PT provider the majority of our results correspond to $Z$-scores lower than 2 .

\subsection{PT 2011.4 Round}

Elemental concentrations obtained by relative and $\mathrm{k}_{0^{-}}$ NAA methods in eight samples of ISE and IPE materials are expressed by $Z$-scores accordingly the Figures 1 and 2. In this test, 30 elements $(\mathrm{Al}, \mathrm{As}, \mathrm{Ba}, \mathrm{Br}, \mathrm{Ca}, \mathrm{Cd}$, $\mathrm{Ce}, \mathrm{Co}, \mathrm{Cr}, \mathrm{Cs}, \mathrm{Fe}, \mathrm{Ga}, \mathrm{K}, \mathrm{La}, \mathrm{Mg}, \mathrm{Mn}, \mathrm{Mo}, \mathrm{Na}, \mathrm{Nd}, \mathrm{Rb}$, $\mathrm{Sb}, \mathrm{Sc}, \mathrm{Se}, \mathrm{Sr}, \mathrm{Th}, \mathrm{Ti}, \mathrm{U}, \mathrm{V}, \mathrm{W}, \mathrm{Zn}, \mathrm{Zr}$ ) are determined in all WEPAL soil and plant samples.

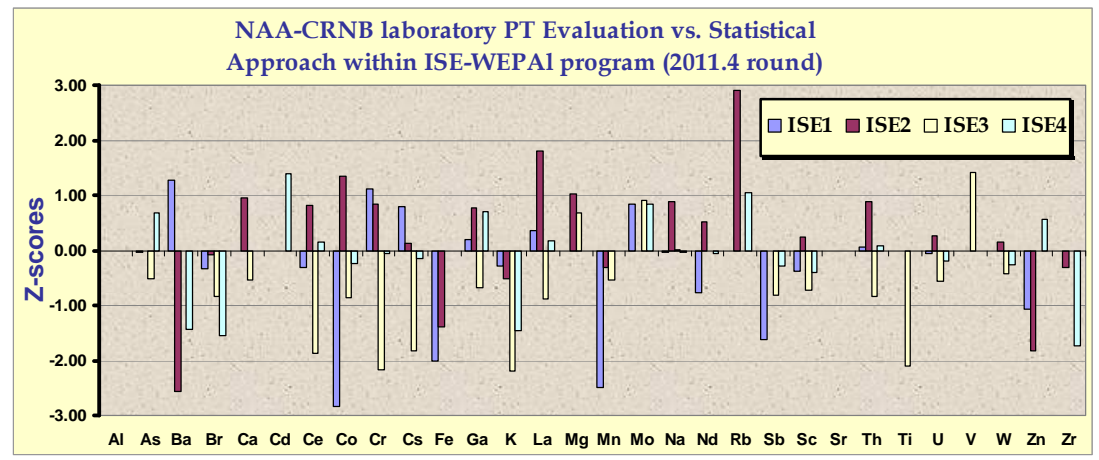

Figure 1. Graphical PT evaluation of the overall z-score results obtained by NAA-CRNB laboratory for 31 elements analyzed in four ISE-WEPAL materials. 


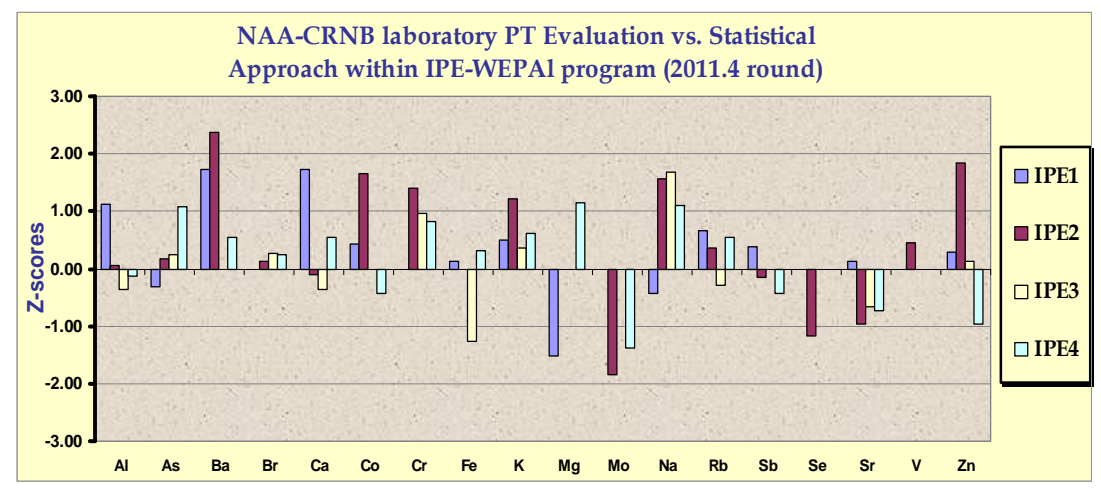

Figure 2. Graphical PT evaluation of the overall z-score results obtained by NAA-CRNB laboratory for 18 elements analyzed in four IPE-WEPAL materials.

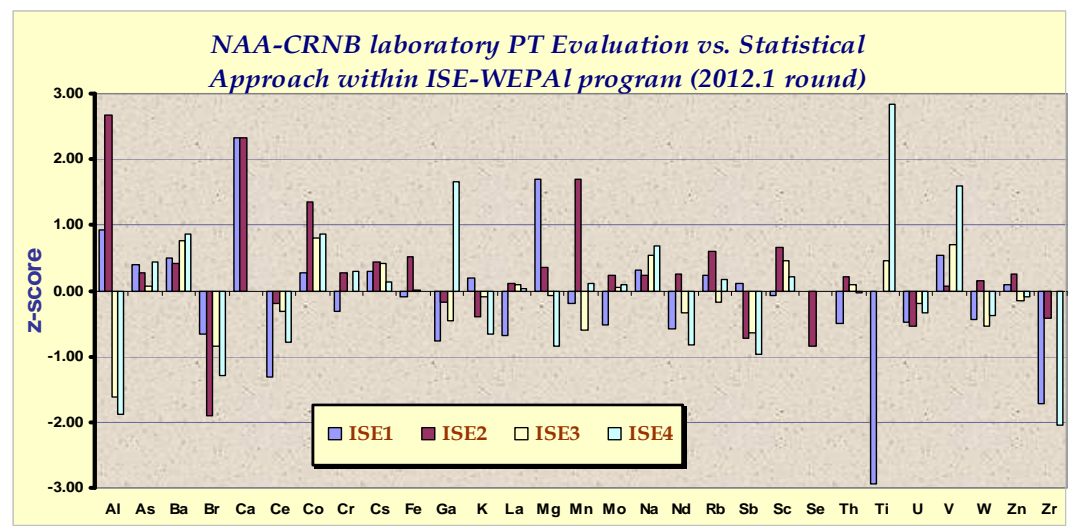

Figure 3. Graphical PT evaluation of the overall z-score results obtained by NAA-CRNB laboratory for 29 elements analyzed in four ISE-WEPAL materials.

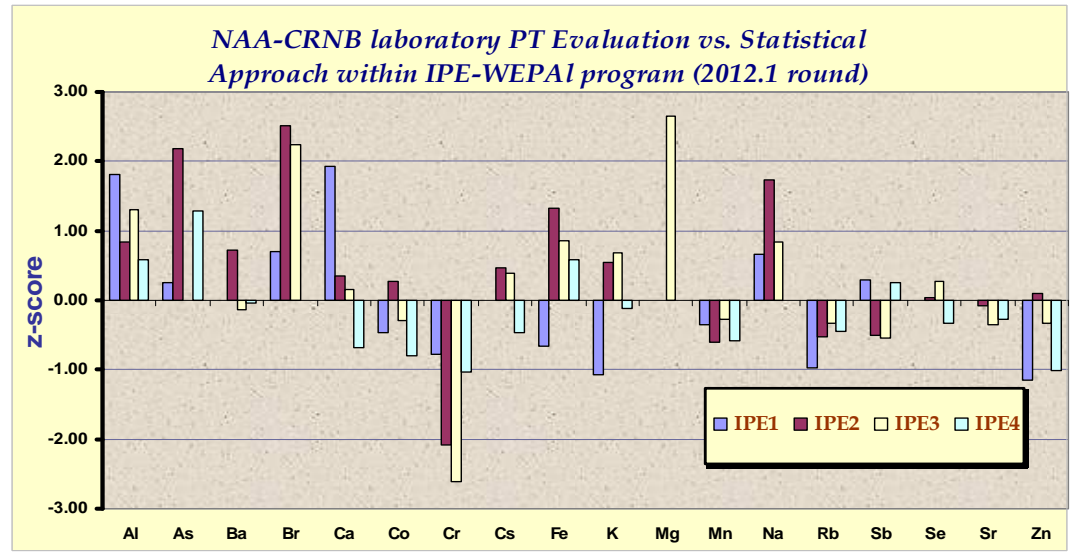

Figure 4. Graphical PT evaluation of the overall z-score results obtained by NAA-CRNB laboratory for 18 elements analyzed in four International Plant Analytical exchange IPE-WEPAL materials.

Two diagrams (Figures 1 and 2) illustrate clearly the quality of our results. These allow extracting numerous information noted bellow:

- About 182 concentration values for plant and soil materials are determined by $\mathrm{k}_{0}$-INAA and INAA methods for the first PT,

- Among the total number of results, 70 and 112 values are reported for IPE and ISE samples, respectively,

- The evaluation of all results revealed that 135 good results having Z-scores lower than 2 from 182 values for which the total success rate is $74.2 \%$.

- In term of biological matrices like IPE, we find 55 good results having a Z-score lower than 2 from 70 data giving about $78.575 \%$ of achievement. 
- For ISE samples, the same observations are noted. The rate of achievement is $71.43 \%$ based on 80 good results from 112 values.

\subsection{PT 2012.1 Round}

The same interpretations can be made for the second PT 2012.1 round. The comparison between two participating proficiency tests gives a significant improvement of our contribution. The number of accepted values determined by NAA method in the second test is relatively higher than the first. Figures $\mathbf{3}$ and $\mathbf{4}$ presented the distribution of Z-scores versus analyzed elements.

The success rate became more important during our second participation in PT of provider. This indicates that the system calibration like calibration of weighing balance, irradiation channels and HPGe detectors were obtained carefully. In a short-term projection our laboratory seeking accreditation, these measures are an important aspect of the requirements. PT is one of these measures, as well as for example, the use of (certified) reference materials. PT plays a highly valuable role as it provides an objective evidence of the competence of the participant. This evidence can be used to improve the performance of the participant and/or give confidence in the participant's ability to perform a specific measurement (Ta- ble 2).

During the participation in PT schemes, it is very interesting to assess the quality of obtained results and to make comparison at different stage. In the Figure 5, the comparison was presented. The comparison between two PT round 2011.4 and 2012.1 revealed that the number of satisfactory results expressed by accepted Z-scores are very important in each round. In addition, an apparent improvement was observed for the second test. This indicates the role of researcher in the improvement of the analytical process.

\section{Conclusions}

One of the basic elements in all PT is the evaluation of the performance of each participant. In order to do so, the PT provider has to establish two values, which are used for the performance evaluation. It is clear that the PT plays a highly valuable role as it provides an objective evidence of the competence of the participant. This evidence can be used to improve the performance of the participant and/or give confidence in the participant's ability to perform a specific measurement.

This paper presents the general state of the NAA analytical laboratory with the considerable efforts of NAA group using Es-Salam research reactor facility.

Table 2. Experimental conditions used in this work.

\begin{tabular}{|c|c|c|c|}
\hline \multirow[b]{2}{*}{ Analyzed material } & Short irradiation channel & \multicolumn{2}{|c|}{ Long irradiation channel } \\
\hline & IPE, GSV4 NIST1573a & ISE, GSD12 Soil7 & IPE, GSV4 Lichen 336 \\
\hline $\begin{array}{l}\text { Neutron spectrum } \\
\text { parameters } \\
\alpha, f, \Phi_{\text {th }}\end{array}$ & $\begin{array}{c}-0.4 \\
159.42 \\
2.261010^{+14}\end{array}$ & $\begin{array}{c}0.027 \\
28.83 \\
4.710^{+12}[2]\end{array}$ & $\begin{array}{c}0.045 \\
20.5 \\
3.7610^{+13}[1]\end{array}$ \\
\hline Irradiation time & $30 \mathrm{sec}$ & $4 \mathrm{H}$ & $8 \mathrm{H}$ \\
\hline Decay time & $10-20 \mathrm{mn}$ & $\begin{array}{c}4-6 d \\
11-12 d\end{array}$ & $\begin{array}{c}6-8 d \\
12-16 d\end{array}$ \\
\hline Counting time & $500 \mathrm{sec}$ & \multicolumn{2}{|c|}{$\begin{array}{l}5400 \mathrm{sec} / 1^{\text {st }} \text { measurement } \\
7200 \mathrm{sec} / 2^{\text {nd }} \text { measurement }\end{array}$} \\
\hline Measured elements & Al, Mg, Mn, Ti, V & $\begin{array}{l}\text { As, } \mathrm{Ba}, \mathrm{Br}, \mathrm{Ca}, \mathrm{Cd}, \mathrm{Ce}, \mathrm{Co}, \mathrm{Cr}, \mathrm{Cs} \\
\mathrm{Fe}, \mathrm{Ga}, \mathrm{K}, \mathrm{La}, \mathrm{Mo}, \mathrm{Na}, \mathrm{Nd}, \mathrm{Rb}, \mathrm{Sb} \\
\text { Sc, Sr, Th, U, W, Zn, Zr }\end{array}$ & $\begin{array}{l}\mathrm{As}, \mathrm{Ba}, \mathrm{Br}, \mathrm{Ca}, \mathrm{Co}, \mathrm{Cr}, \mathrm{Cs} \text {, } \\
\mathrm{Fe}, \mathrm{K}, \mathrm{Mg}, \mathrm{Mn}, \mathrm{Na}, \mathrm{Rb}, \mathrm{Sb}, \\
\text { Se, Sr, Zn }\end{array}$ \\
\hline
\end{tabular}

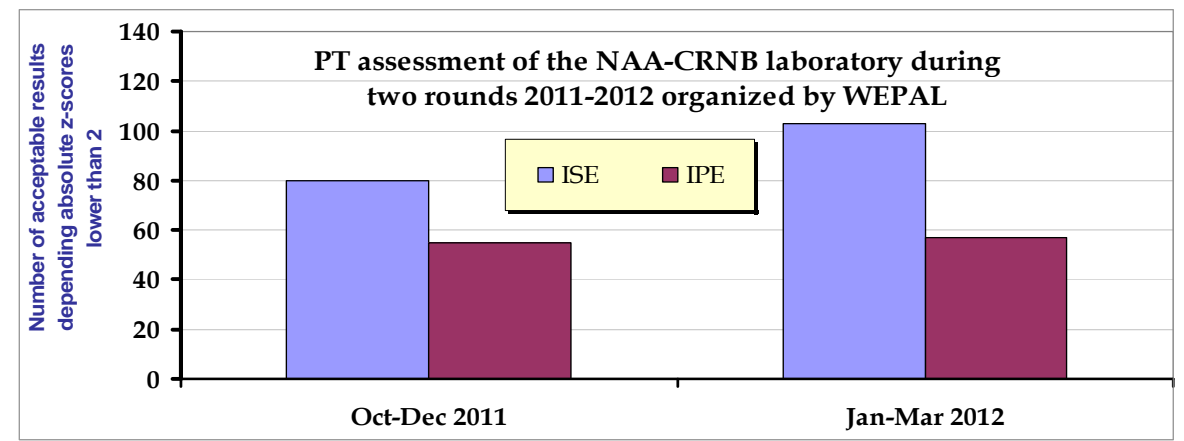

Figure 5. Proficiency test assessment of the NAA laboratory results obtained two rounds 2011.4 and 2012.1. 
During the last decade, we acquired a good experiment through our participations in the proficiency tests program and the inter-comparison exercises which were carried out within the framework of the AFRA/RAF projects. In particular, we agreed that the objectives of the IAEA in facilitating these PT rounds under the project $\mathrm{RAF} / 4 / 022$ were achieved. These remains strongly recommend that the IAEA continues to facilitate new PT Rounds with feedback meetings for independent assessment of performance of analytical laboratories. In addition, in the first participation with WEPAl organization we got a clear understanding of the procedures and methodology of PT rounds, and a mechanism for their own evaluation of the outcome thereof.

\section{Acknowledgements}

This work has been carried out at Es-Salam Research reactor under the framework of AFRA-RAF/4/022 project. We are thankful to the International Atomic Energy Agency for financial support. We also would like to thank Dr Danas Ridikas and Pr Peter Bode for their valuable discussions. Thanks are due to Mhamed Salhi, national coordinator for RAF4/022 project and the NAA group of CRNB and our colleagues from the division of nuclear techniques and applications for their assistance during the experiments.

\section{REFERENCES}

[1] L. Alghem, M. Ramdhane, S. Khaled and T. Akhal, "The Development and Application of $\mathrm{K}_{0}$-Standardization Method of Neutron Activation Analysis at Es-Salam Research Reactor," Journal of Nuclear Instruments and Methods in Physics Research Section A, Vol. 556, No. 1, 2006, pp. 386-390.

[2] L. Hamidatou and M. Ramdhane, "Characterization of Neutron Spectrum at Es-Salam Research Reactor Using Høgdahl Convention and Westcott Formalism for the $\mathrm{K}_{0^{-}}$ Based Neutron Activation Analysis," Journal of Radioanalytical and Nuclear Chemistry, Vol. 278, No. 3, 2008, pp. 627-630.

[3] L. Hamidatou and H. Benkharfia, "Experimental and MCNP Calculations of Neutron Flux Parameters in Irradiation Channel at Es-Salam Reactor," Journal of Radioanalytical and Nuclear Chemistry, Vol. 287, No. 3, 2011, pp. 971-975.

http://dx.doi.org/10.1007/s10967-010-0922-9

[4] L. A. Hamidatou, S. Dakar and S. Boukari, "K $\mathrm{K}_{0} \mathrm{NAA}$ Quality Assessment in an Algerian Laboratory by Analysis of SMELS and Four IAEA Reference Materials Using Es-Salam Research Reactor," Journal of Nuclear Instruments and Methods in Physics Research Section A, Vol. 682, 2012, pp. 75-78.

[5] L. A. Hamidatou, S. Khaled, M. Mouzai, B. Zouranen, A. Ararem, A. Alghem and M. Ramdhane, "Instrumental Neutron Activation Analysis of Milk Samples Using the
$\mathrm{K}_{0}$-Standardization Method at Es-Salam Research Reactor," Physical and Chemical News, Vol. 45, 2009, pp. 4447.

[6] L. A. Hamidatou, S. Khaled, T. Akhal and M. Ramdhane, "Determination of Trace Elements in Cigarette Tobacco with the $\mathrm{K}_{0}$-Based NAA Method Using Es-Salam Research Reactor," Journal of Radioanalytical and Nuclear Chemistry, Vol. 281, No. 3, 2009, pp. 535-540. http://dx.doi.org/10.1007/s10967-009-0011-0

[7] S. Khaled, M. Mouzai, A. Ararem, L. Hamidatou and B. Zouranen, "Elemental Analysis of Traditional Medicinal Seeds by Instrumental Neutron Activation Analysis," Journal of Radioanalytical and Nuclear Chemistry, Vol. 281, No. 1, 2009, pp. 87-90.

http://dx.doi.org/10.1007/s10967-009-0076-9

[8] L. Hamidatou Alghem, "Mise au Point de la Méthode $\mathrm{K}_{0^{-}}$ NAA en Utilisant la Convention de H申GDAHL et le Formalisme de WESTCOTT et son Application dans la Nutrition, la Santé et la Minéralogie," Ph.D Thesis, Ferhat Abbes University, 2010.

[9] L. Hamidatou, H. Slamene, T. Akhal and B. Zouranen, "Concepts, Instrumentation and Techniques of Neutron Activation Analysis," In: F. Kharfi, Ed., Imaging and Radioanalytical Techniques in Interdisciplinary ResearchFundamentals and Cutting Edge Applications, InTech, Rijeka, 2013, pp. 141-178.

http://www.intechopen.com/books/imaging-and-radioanal yal-techniques-in-interdisciplinary-research-fundamentals -and-cutting-edge-applications/concepts-instrumentationand-techniques-of-neutron-activation-analysis http://dx.doi.org/10.5772/53686

[10] S. Khaled, S. Belaid, M. Mouzai, L. Alghem, A. Ararem and B. Zouranen, "Development and Application of the Cyclic Delayed Neutron Counting Technique at Es-Salam Research Reactor," Physical and Chemical News, Vol. 45, 2009, pp. 39-43.

[11] T. Akhal, M. Mouzai, Y. Sana and M. Ladjel, "Application of RNAA to the Proportioning of Iodine in Food Salt," The Journal of Physical Chemistry A, Vol. 45, 2009, pp. 34-38.

[12] ISO 5725-1994, "Accuracy (Trueness and Precision) of Measurement Methods and Results".

[13] ISO/IEC 17025:2005, "General Requirements for the Competence of Testing and Calibration Laboratories".

[14] ISO 15189:2007, "Medical laboratories-Particular Requirements for Quality and Competence".

[15] EURACHEM, "Selection, Use and Interpretation of Proficiency Testing (PT) Schemes," 2nd Edition, 2011.

[16] I. Taverniers, M. De Loose, E. Van Bockstaele, "Trends in Quality in the Analytical Laboratory. II. Analytical Method Validation and Quality Assurance," TrAC Trends in Analytical Chemistry, Vol. 23, No. 8, 2004, pp. 535552. http://dx.doi.org/10.1016/j.trac.2004.04.001

[17] IAEA/AFRA Project RAF /4/022, Summary Report-Nuclear Sciences and Applications, 31 March 2013.

[18] WEPAL, 2013. www.wepal.nl

[19] A. Barzev and A. Faanhof, "A Proficiency Test Study under the AFRA IV-7 Project Cmip-Afra-P1: Trace and 
Minor Elements in Geological Materials. Report to participants," NECSA, 2013.

[20] M. Mouzai and T. Akhal, "Inter-Comparison Feedback Meeting: A Proficiency Test Study under the AFRA IV-7 Project Trace and Minor Elements in Geological Materials," Algiers, 29 November-3 December 2003.

[21] A. Faanhof, "Document RA-07013 (Rev 00) (2006) AFRA IV-7 Proficiency Test 2005: Essential and Toxic Elements in Foodstuffs," NECSA.

[22] M. Mouzai and T. Akhal, "Inter-Comparison Feedback Meeting: A proficiency Test Study under the AFRA IV-7 Project Medicinal Plants and the Analysis of AquaticBiomonitors for Environmental Monitoring," Lybia, 2005.

[23] A. Faanhof, "Document RA-07013 (Rev 00) (2008) AFRA IV-12 Inter-Laboratory Analysis Test 2007: Essential and Toxic Elements in Foodstuffs, Medicinal Plants and Aquatic Biomonitors," NECSA.

[24] L. Hamidatou Alghem, S. Khaled and B. Zouranen, "Elemental Determination of Five Materials Representing Foodstuff, Medicinal Plants and Aquatic Biomonitors Using $\mathrm{K}_{0}$-INAA Method: Meeting on the First Results Inter-Laboratory Competency Test AFRA IV-12 Project, RAF/4/020," Kenitra, 14-18 July 2008.

[25] M. Mouzai and T. Akhal, "Elemental Determination of Five Materials Representing Foodstuff, Medicinal Plants and Aquatic Biomonitors by Relative: Meeting on the First Results Inter-Laboratory Competency Test AFRA IV-12 Project, RAF/4/020," Kenitra, 14-18 July 2008.

[26] L. Hamidatou, T. Akhal, H. Slamene and Z. Boussad, "The Proficiency Testing Tests Related to the Determina- tion of Major, Minor and Trace Elements in Materials of the International Soil and Plant Analytical Exchange Material of WEPAL," Meeting on Inter-Comparison FeedBack of NAA and Other Analytical Techniques Proficiency Tests, AIEA Project/RAF4022-Enhancing Research Reactor Utilization and Safety, 4-8 June 2012, Tunis.

[27] Quarterly Report 2011.4, "International Plant-Analytical Exchange," Wageningen University (Environmental Sciences), Wageningen. Prof Testing RvA R 002.

[28] Quarterly Report 2011.4, "International Soil-Analytical Exchange," Wageningen University (Environmental Sciences), Wageningen. Prof Testing RvA R 002.

[29] Quarterly Report 2012.1, "International Plant-Analytical Exchange," Wageningen University (Environmental Sciences), Wageningen. Prof Testing RvA R 002.

[30] Quarterly Report 2012.1, “International Soil-Analytical Exchange," Wageningen University (Environmental Sciences), Wageningen. Prof Testing RvA R 002.

[31] Genie $\mathrm{GM}^{\mathrm{TM}} 2000$ Spectroscopy Software, Version 3.2.1, Canberra, 2009.

[32] HyperLab 2005 System: Installation and Quick Start Guides. HyperLabs Software, Budapest, 2005.

[33] Kayzero for Windows (KayWins) 2005 Software Package for Reactor Neutron Activation Analysis (NAA) Using the $\mathrm{K}_{0}$-Standardization Method, Version 2, Software Developed by DSM Research, Geleen (NL) for NAA Based on the $\mathrm{K}_{0}$-Standardization Method Developed at the INW-RUG, Gent (B) and the AEKI, Budapest (H). 